\title{
Forecasting Stock Exchange Movements Using Artificial Neural Network Models and Hybrid Models
}

\author{
Erkam GÜREŞEN and Gülgün KAYAKUTLU \\ Istanbul Technical University, Department of Industrial Engineering, \\ Maçka, 34367 Istanbul, Turkey. \\ erkamguresen@gmail.com \\ kayakutlu@itu.edu.tr
}

\begin{abstract}
Forecasting stock exchange rates is an important financial problem that is receiving increasing attention. During the last few years, a number of neural network models and hybrid models have been proposed for obtaining accurate prediction results, in an attempt to outperform the traditional linear and nonlinear approaches. This paper evaluates the effectiveness of neural network models; recurrent neural network (RNN), dynamic artificial neural network (DAN2) and the hybrid neural networks which use generalized autoregressive conditional heteroscedasticity (GARCH) and exponential generalized autoregressive conditional heteroscedasticity (EGARCH) to extract new input variables. The comparison for each model is done in two view points: MSE and MAD using real exchange daily rate values of Istanbul Stock Exchange (ISE) index XU10).
\end{abstract}

\section{Introduction}

The financial time series models expressed by financial theories have been the basis for forecasting a series of data in the twentieth century. Yet, these theories are not directly applicable to predict the market values which have external impact. The development of multi layer concept allowed ANN (Artificial Neural Networks) to be chosen as a prediction tool besides other methods. Various models have been used by researchers to forecast market value series by using ANN (Artificial Neural Networks). Engle (1982) suggested the ARCH(p) (Autoregressive Conditional Heteroscedasticity) model, Bollerslev (1986) generalized the ARCH model and proposed the GARCH (Generalized ARCH) model. By considering the leverage effect limitation of the GARCH model, the EGARCH (Expo- 
nential GARCH) model was proposed (Nelson 1991). Despite the popularity and implementation of the ANN models in many complex financial markets directly, shortcomings are observed. The noise that caused by changes in market conditions, it is hard to reflect the market variables directly into the models without any assumptions (Roh 2007). During the last few years research is focused on improving the ANN's prediction performance.

The objective of this study is to compare classical ANN models and new ANN methodologies with hybrid ANN models, such as GARCH-ANN and EGARCHANN models. The methods are compared by using MSE (Mean Square Error), MAD (Mean Absolute Deviation) and \% MAD (Mean Absolute \% Deviation).

The remaining sections of this paper are organized as follows: Section 2 provides a brief review of related studies. Section 3 introduces the models used in this study and Section 4 provides results of each model using daily exchange rates of Istanbul Stock Exchange (ISE) index XU100. Final section concludes the study with future researches.

\section{Brief review of research on time series}

ANN models have been used by researchers. A brief literature survey is given in Table 1. This survey clearly shows that ANN methods outperform the classical methods. Hybrid methods that use both classical methods with ANN have potential to avoid deficiencies in classical methods.

Many researchers pointed that hybrid methods are promising for future studies and with using hybrid methods advantages of each method can combine. 
Table 1. Financial Time Series Researches (ANN and Hybrid Models)

\begin{tabular}{|c|c|c|c|c|c|c|c|c|c|c|c|}
\hline : & 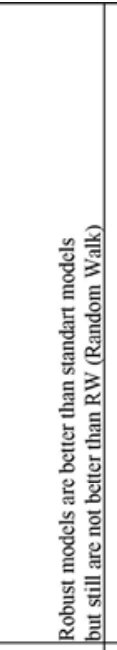 & 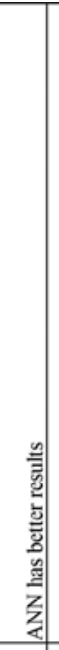 & 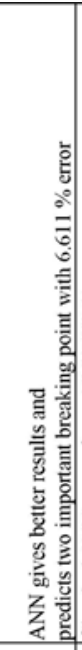 & 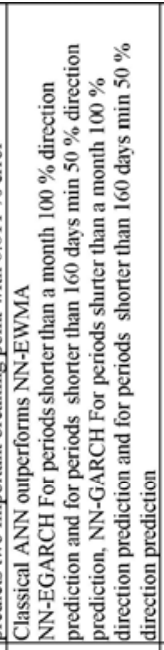 & 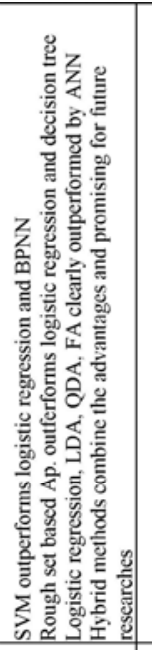 & 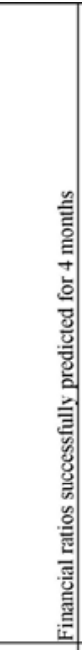 & 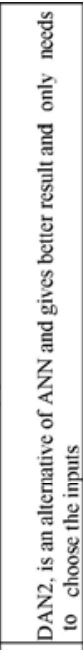 & 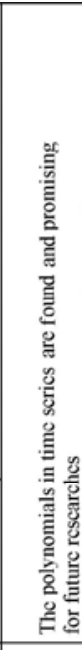 & 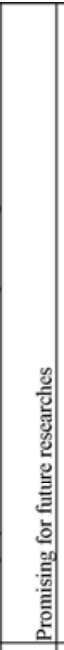 & 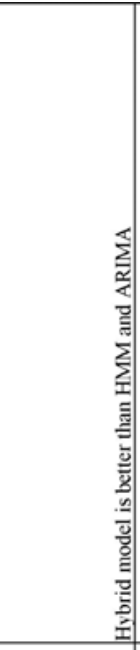 & 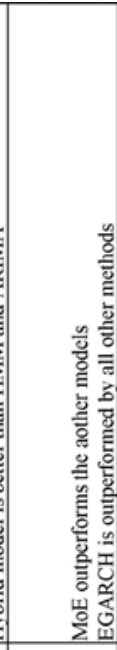 \\
\hline . & 诘言 & 気 & हे & 츰 & & & & & $\begin{array}{l}0 \\
0 \\
0 \\
0\end{array}$ & 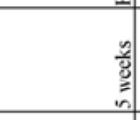 & \\
\hline (\zh14) & 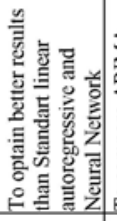 & 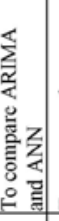 & 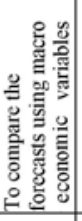 & 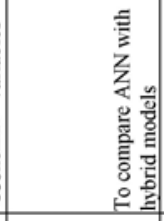 & 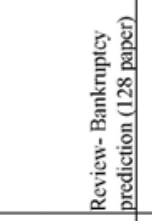 & 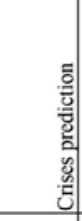 & 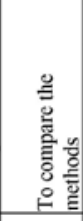 & 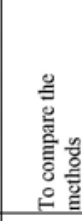 & 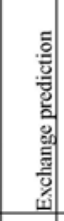 & 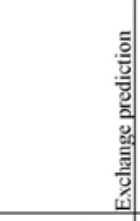 & 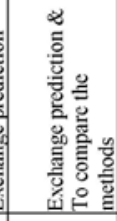 \\
\hline 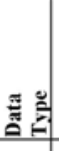 & 商氛 & 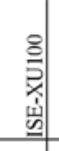 & 放 & $\begin{array}{l}\stackrel{0}{0} \\
\hat{0} \\
0 \\
\end{array}$ & & 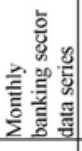 & 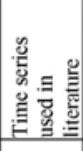 & 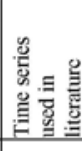 & 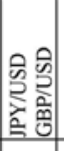 & 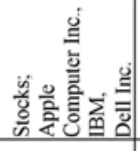 & $\begin{array}{l}\text { 总 } \\
\text { 鄫 }\end{array}$ \\
\hline 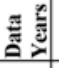 & 㸃壳 & & ڤે & 家害 & & \% & & & ڤె & 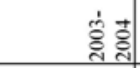 & \\
\hline 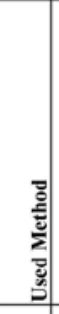 & 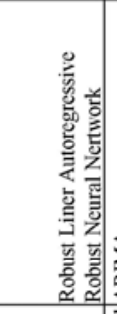 & 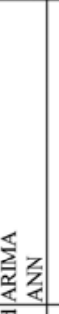 & 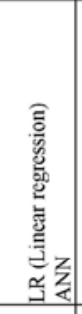 & 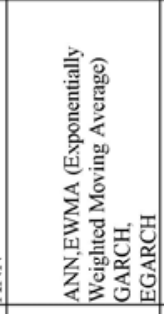 & 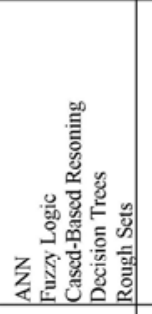 & z & 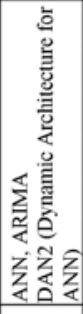 & 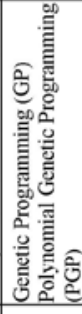 & 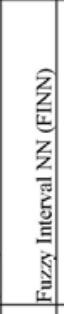 & 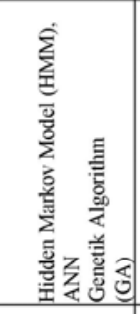 & 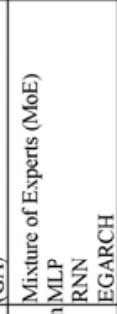 \\
\hline 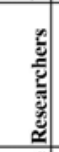 & 总 & 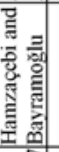 & 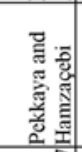 & 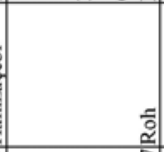 & 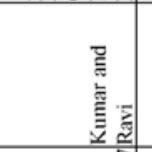 & 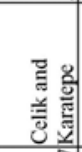 & 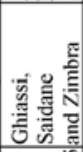 & 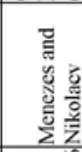 & 㩆 & 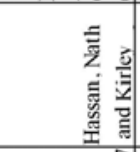 & 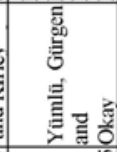 \\
\hline : & 길 & 월 & : & ते & 원 & : & $\beth$ & ङ્ & 원 & : & \\
\hline
\end{tabular}




\section{ANN and Hybrid ANN Models}

\subsection{Multilayer Perceptron (MLP)}

This model uses last four values of a time series as inputs and generated by using NeuroSolutions 5.06 software. MLP has two layers using tanh neurons. The number of neurons in each layer and learning rate are calculated by genetic algorithm using the same software.

\subsection{Lagged Time Series (LTS)}

This model is generated by using NeuroSolutions 5.06 software to use lagged values of the financial time series. LTS has 2 layers with tanh neurons and each layer have lagged connections. The number of neurons in each layer and learning rate are calculated by genetic algorithm using the same software.

\subsection{Recurrent Neural Network (RNN)}

This model is generated by using NeuroSolutions 5.06 software to have 2 layers with tanh neurons and each layer consisting of recurrent connections. The number of neurons in each layer and learning rate are calculated by genetic algorithm using the same software.

\subsection{Dynamic Architecture for Artificial Neural Networks (DAN2)}

This model is developed by Ghiassi and Saidane (Ghiassi and Saidane 2005) and compared with the classical ANN models using a known time series (Ghiassi et al. 2005). Figure 1 shows the structure of DAN2.

DAN2 uses all input data at a time to train the network. Training begins with a special $\mathrm{F}_{0}$ node captures the linearity using classical linear regression. The training process stops when a desired level of accuracy is reached. Each time a nonlinear relation is hit, a new hidden layer is added. Each hidden layer has 4 nodes: one $\mathrm{C}$ node, one CAKE node (in Figure 1, F nodes) and two CURNOLE nodes (in Figure $1, \mathrm{G}$ and $\mathrm{H}$ nodes). A CAKE (Current Accumulated Knowledge Element) node captures the previous layers using the CAKE node at the previous layer. 
With a linear combination of CURNOLE (Current Residual Nonlinear Element) nodes, $\mathrm{C}$ node and previous CAKE node, existing CAKE node provides the results. Until the desired level of accuracy reached new hidden layers continue to be added to the model. After the special linear layer $\left(\mathrm{F}_{0}\right)$ DAN2 uses $\alpha_{i}$ 's where $\alpha_{i}$ is the angle between the observation vector $i$ and a defined reference vector. DAN2 uses the trigonometric transfer functions to capture the nonlinearity. Each $G$ and $H$ nodes at layer $k$ uses the given formula:

$G_{k}\left(X_{i}\right)=\operatorname{Cosine}\left(\mu_{i} \times \alpha_{i}\right), \mathrm{H}_{k}\left(\mathrm{X}_{i}\right)=\operatorname{Sine}\left(\mu_{i} \times \alpha_{i}\right)$

Using the given formula of $G_{k}\left(X_{i}\right)$ and $H_{k}\left(X_{i}\right)$ we can use the following formula for F nodes:

$F_{k}\left(X_{i}\right)=a_{k}+b_{k} F_{k-1}\left(X_{i}\right)+c_{k} \operatorname{Cosine}\left(\mu_{i} \times \alpha_{i}\right)+d_{k} \operatorname{Sinse}\left(\mu_{i} \times \alpha_{i}\right)$

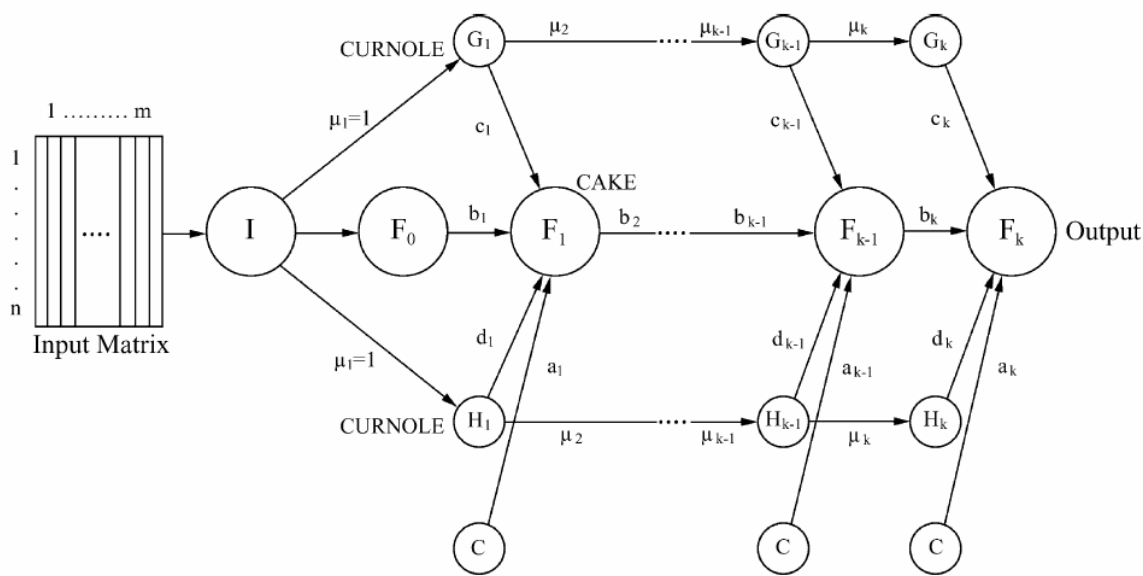

Fig. 1. The DAN2 Network Architecture (Ghiassi and Saidane 2005) 


\subsection{GARCH - ANN Models}

Most of the financial series models are known to be easily modelled by $\operatorname{GARCH}(1,1)$, so this research uses the extracted variables from $\operatorname{GARCH}(1,1)$ as Roh suggests (Roh 2007). The GARCH(1,1) has the following formula:

$\sigma_{\mathrm{t}}^{2}=\alpha_{0}+\alpha_{1} \varepsilon_{\mathrm{t}-1}^{2}+\beta_{1} \sigma_{\mathrm{t}-1}^{2}$

Where $\sigma_{t}$ is volatility at $t, \alpha_{0}$ is the non-conditional volatility coefficient, $\varepsilon_{t-1}^{2}$ residual at $t-1, \sigma_{t-1}{ }^{2}$ is the variance at $t-1$.

The newly extracted variables are as follows (Roh 2007):

$-\sigma_{\mathrm{t}}^{2}=\beta_{1} \sigma_{\mathrm{t}-1}^{2}$

$-\quad \varepsilon_{\mathrm{t}-1}{ }^{2}=\alpha_{1} \varepsilon_{\mathrm{t}-1}{ }^{2}$

We use these new variables as additional inputs for every type of ANN given above.

\subsection{EGARCH - ANN Models}

EGARCH has the leverage effect with the following formula:

$$
\ln \sigma_{t}^{2}=\alpha+\beta \ln \sigma_{t-1}^{2}+\gamma\left(\left|\frac{\varepsilon_{t-1}}{\sigma_{t-1}}-\sqrt{\frac{2}{\pi}}\right|\right)+\omega\left(\frac{\varepsilon_{t-1}}{\sigma_{t-1}}\right)
$$

Where $\alpha$ is the non-conditional variance coefficient, $\ln \sigma_{t}^{2}$ is the $\log$ value of variance at $t-1,\left(\left|\varepsilon_{t-1} / \sigma_{t-1}-\sqrt{ }(2 / \pi)\right|\right)$ is the asymmetric shock by leverage effect, and $\left(\varepsilon_{t-1} / \sigma_{t-1}\right)$ is the leverage effect. The newly extracted variables are as follows (Roh 2007):

$-\quad \ln \sigma_{\mathrm{t}}^{2}=\beta \ln \sigma_{\mathrm{t}-1}^{2}$

- LE (leverage effect) $=\gamma\left(\left|\varepsilon_{t-1} / \sigma_{t-1}-\sqrt{ }(2 / \pi)\right|\right)$

$-\quad \mathrm{L}($ leverage $)=\omega\left(\varepsilon_{\mathrm{t}-1} / \sigma_{\mathrm{t}-1}\right)$

\section{Forecasting ISE XU100 Index}

In this research daily stock exchange rates of ISE index XU100 from January 2003 to March 2008 are used. Graph of the data is given in figure 2. First 1132 
days are used for training and cross validation and last 160 used for testing. For hybrid models also new variables extracted from GARCH and EGARCH are calculated using MS Excel. For MLP, LTS, RNN, GARCH-MLP, GARCH-LTS, GARCH-RNN, EGARCH-MLP, EGARCH-LTS and EGARCH-RNN NeuroSolutions 5.06 software is used. For calculating DAN2, GARCH-DAN2 and EGARCH-DAN2 MS Excel is used. Results are given in table 2. GARCH-DAN2 have the smallest training MSE and MAD, followed by EGARCH-DAN2 and DAN2. In all the other hybrid models, training MSE and MAD values are increased. However, GARCH-DAN2 and EGARCH-DAN2 have smaller training MSE and MAD, DAN2 has smaller testing MSE and MAD. DAN2 based neural networks outperformed the other neural networks. Hybrid RNN models decrease the training error but increase the testing errors.

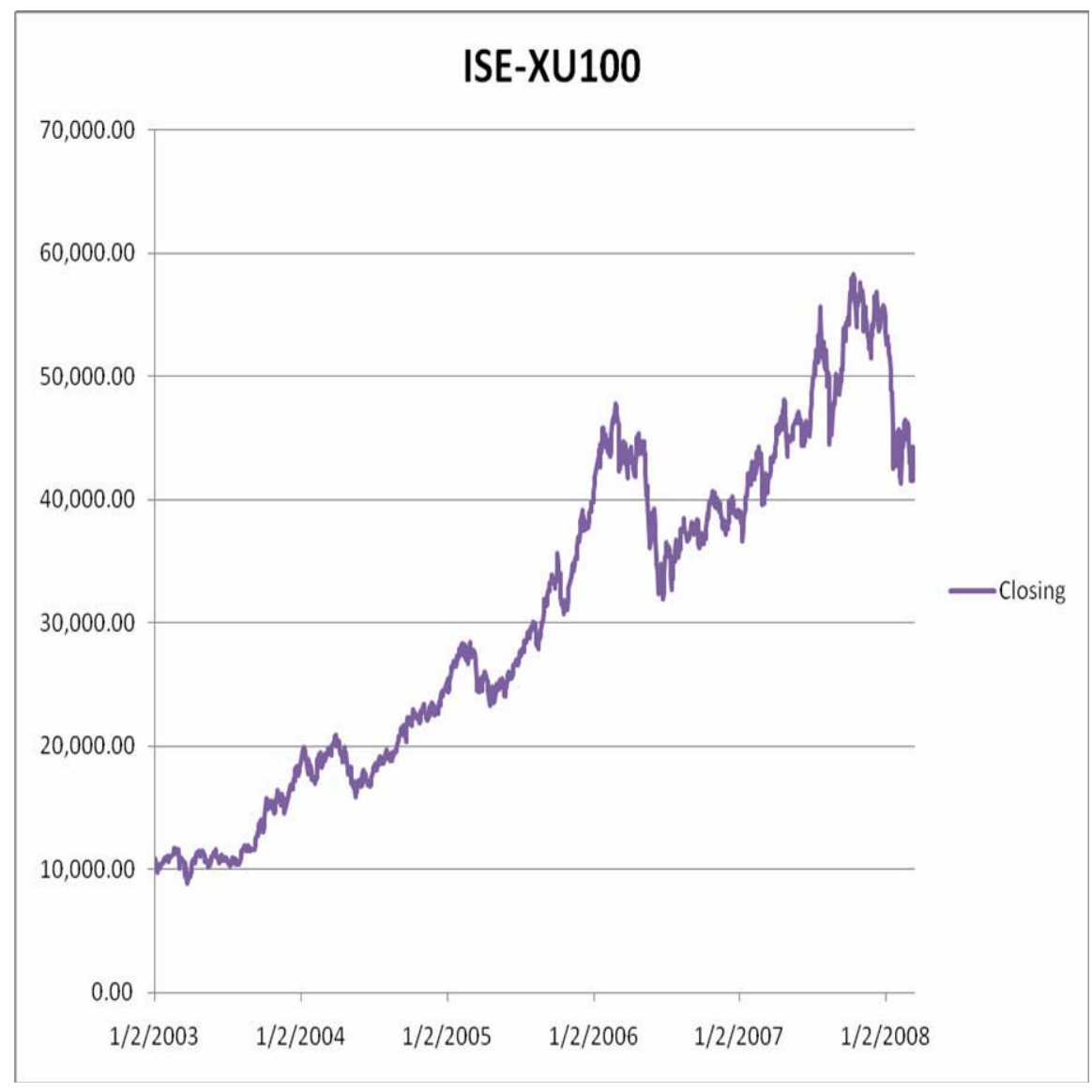

Fig. 2. ISE XU100 closing values from January 2003 to March 2008 
Table 2. Results of ANN and Hybrid Models

\begin{tabular}{|l|l|l|l|l|l|l|}
\cline { 2 - 7 } \multicolumn{1}{c|}{} & \multicolumn{1}{l}{ Training } & \multicolumn{1}{l}{ Test } \\
\cline { 2 - 7 } \multicolumn{1}{l|}{ MSE } & MAD & MAD \% & MSE & MAD & MAD \% \\
\hline MLP & $332,121.4$ & 431.074 & 2.02378 & $5,540,545.9$ & $2,042.031$ & 3.87061 \\
\hline LTS & $4,040,290.2$ & $1,270.136$ & 8.091805 & $4,053,666.2$ & $3,114.716$ & 6.021672 \\
\hline RNN & $2,215,589.2$ & $1,073.526$ & 6.182388 & $30,728,867.0$ & $4,748.948$ & 8.847816 \\
\hline DAN2 & $262,130.4$ & 370.661 & 1.408297 & $1,176,015.7$ & 840.700 & 1.679289 \\
\hline $\begin{array}{l}\text { GARCH- } \\
\text { MLP }\end{array}$ & $468,823.2$ & 514.225 & 2.627341 & $7,124,780.4$ & $2,317.443$ & 4.38835 \\
\hline $\begin{array}{l}\text { EGARCH- } \\
\text { MLP }\end{array}$ & $450,787.2$ & 512.206 & 2.705861 & $8,651,756.5$ & $2,547.234$ & 4.797743 \\
\hline $\begin{array}{l}\text { GARCH- } \\
\text { LTS }\end{array}$ & $4,793,112.9$ & $1,344.516$ & 7.021188 & $82,679,183.4$ & $8,259.680$ & 15.56614 \\
\hline $\begin{array}{l}\text { EGARCH- } \\
\text { LTS }\end{array}$ & $7,268,783.3$ & $1,771.432$ & 9.802969 & $86,388,074.0$ & $8,383.227$ & 15.77058 \\
\hline $\begin{array}{l}\text { GARCH- } \\
\text { RNN }\end{array}$ & $1,588,036.6$ & 839.538 & 4.413098 & $40,952,240.9$ & $5,621.619$ & 10.52457 \\
\hline $\begin{array}{l}\text { EGARCH- } \\
\text { RNN }\end{array}$ & $2,331,406.0$ & 806.284 & 4.545228 & $46,952,272.1$ & $5,970.485$ & 11.15228 \\
\hline $\begin{array}{l}\text { GARCH- } \\
\text { DAN2 }\end{array}$ & $261,378.6$ & 370.218 & 1.4039 & $1,178,820.5$ & 842.373 & 1.682031 \\
\hline $\begin{array}{l}\text { EGARCH- } \\
\text { DAN2 }\end{array}$ & $261,918.2$ & 370.416 & 1.405955 & $1,177,072.3$ & 841.188 & 1.680164 \\
\hline
\end{tabular}

\section{Conclusion}

This study is in search for reducing the shortcomings of using ANN in predicting the market values. With this aim Hybrid models are developed and investigated. In order to present the differences in accuracy of prediction, all the models are applied on the same set of data retrieved from Istanbul Stock exchange.

This study shows that DAN2 is powerful neural network architecture. Hybrid models using GARCH and EGARCH can decrease the training error but do not guarantee a decrease in testing errors. The lowest error is achieved by DAN2 based hybrid model, which also shows that DAN2 has greater noise tolerance.

The achieved results indicate that DAN2 model is to be focused in the future studies to improve the noise tolerance. More attention is to be given to the hybrid models in defining the hybridization procedure clearly. 


\section{References}

1. Bollerslev, T., "Generalized autoregressive conditional heteroscedasticity", Journal of Econometrics, vol 31, 1986, p. 307-327.

2. Celik A. E., Karatepe Y., "Evaluating and forecasting banking crises through neural network models: An application for Turkish banking sector", Expert systems with Applications, vol. 33, 2007, p. 809-815.

3. Engle R. F., "Autoregressive conditional heteroscedasticity with estimator of variance of United Kingdom inflation”, Econometrica, 1982, 50(4), p. 987-1008.

4. Ghiassi M., Saidane H., "A dynamic architecture for artificial neural networks", Neurocomputing, vol. 63, 2005, p. 397-413.

5. Ghiassi M., Saidane H., Zimbra D.K., "A dynamic artificial neural network model for forecasting time series events", International Journal of Forecasting, vol. 21, 2005, p. 341-362.

6. Hassan M. R., Nath B., Kirley M., "A fusion model of HMM,ANN and GA for stock market forecasting”, Expert Systems with Applications, vol. 33, 2007, p. 171-180.

7. Kumar P. R., Ravi V., "Bankruptcy prediction in banks and firms via statistical and intelligent techniques - A rewiev", European Journal of Operational Research, vol. 180, 2007, p. 1-28.

8. Menezes L. M., "Forecasting with genetically programmed polynomial neural networks", International Journal of Forecasting, vol. 22, 2006, p. 249-265.

Nelson D. B., "Conditional heterosdasticity in asset returns: a new approach", Econometrica, 1991, 59(2), p. 347-370.

9. Pekkaya M., Hamzaçebi C., "Yapay sinir ağları ile döviz kuru tahmini üzerine bir uygulama", YA/EM 27. National Congress, Izmir 2007, p. 973-978.

10. Preminger A., Raphael F., "Forecasting exchange rates: A robust regression approach", International Journal of Forecasting, vol. 23, 2007, p. 71-84.

11. Roh T. H., "Forecasting the volatility of stock price index", Expert Systems with Applications, vol. 33, 2007, p. 916-922.

12. Zhang Y., Wan X., "Statistical fuzzy interval neural networks for currency exchange rate time series prediction", Applied Soft Computing, vol. 7, 2007, p.1149-1156.

A

ANN (Artificial Neural Networks), 2

D

Dynamic Architecture for Artificial Neural Networks (DAN2), 4

\section{E}

EGARCH, 2

EGARCH - ANN Models, 6

G

GARCH, 2
GARCH - ANN Models, 6

$\mathbf{H}$

Hybrid ANN Models, 4

L

Lagged Time Series (LTS), 4

M

Multilayer Perceptron (MLP), 4

$\mathbf{R}$

Recurrent Neural Network (RNN), 4 